AMERICAN JOURNAL OF REPRODUCTIVE IMMUNOLOGY AND MICROBIOLOGY 18:17-20 당 1988 ALAN R. LISS, INC.

Associate Editor

Richard Bronson

REVIEW

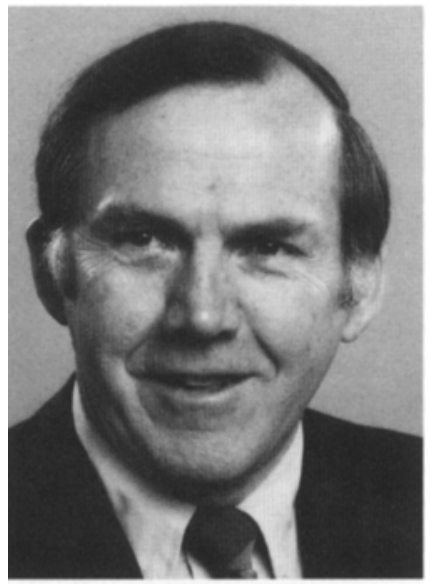

Alan C. Menge

\section{Immunologic Reactions Involving Sperm Cells and Preimplantation Embryos}

ALAN C. MENGE AND RAJESH K. NAZ

Department of Obstetrics and Gynecology, University of Michigan Medical Center, Ann Arbor (A.C.M.); Department of Obstetrics and Gynecology, Albert Einstein College of Medicine, Bronx, New York (R.K.N.)

Evidence that sperm cells share or impart antigenic specificities to fertilized ova and cleaving embryos in animals was first demonstrated indirectly in female animals isoimmunized against sperm or testis cells. While early studies often gave conflicting results, postfertilization infertility effects were occasionally reported. ${ }^{1}$ The systematic analysis in animals of antifertility effects after immunization with sperm or testis preparations resulted in a clearer delineation of the affected stages and modes of action.

In a study of the effects of antisperm antisera on the fertility of sperm in rabbits, Kiddy et al. reported that a dilution of serum that permitted near-normal fertilization rates resulted in significantly lowered levels of embryo survival. ${ }^{2}$ Isoimmunization of female animals with sperm or testis preparations has often produced inconsistent results regarding the degree and stage at which infertility occurs; however, studies in which antifertility

By invitation.

Address reprint requests to Alan C. Menge, Ph.D., Department of Obstetrics and Gynecology, The University of Michigan Medical Center, Ann Arbor, MI 48109 .

\section{AJRIM

effects were carefully evaluated noted an increased preimplantation loss of embryos. Behrman and associates in a series of articles on guinea pigs $s^{3,4}$ and rabbits ${ }^{5}$ and Kiddy and Rollins on guinea pigs ${ }^{6}$ found that immunization with sperm cells had little effect on fertilization rates but caused dramatic postfertilization losses. Similarly, Tung et al. reported that postfertilization infertility was the major effect observed in a study on female mice immunized with sperm. ${ }^{7}$

In experiments on cattle and rabbits we observed that isoimmunization of females with sperm or testis, but not seminal plasma (vasectomy), produced severe inhibition of fertilization; if fertilization did occur, the resultant embryos had a reduced chance of surviving to term. ${ }^{8}$ In studies on cattle, heifers were sensitive to a single immunization of sperm up through 19 days after insemination; the majority $(88 \%)$ returned to estrus and many had prolonged estrus cycles, whereas only $20 \%$ of the control heifers did not conceive. All nine heifers immunized at 21 days or later remained pregnant, suggesting a stage-specific sensitivity to the immune response against sperm cells. In rabbit studies, females immunized against semen and testis had embryo (9 days) and fetal (28 days) survival rates of $67 \%$ and $38 \%$ or less, respectively, than those of appropriate controls. This postfertilization antifertility effect was clearly demonstrated by the poor survival of fertilized ova transferred to the oviducts of sperm- or testis-immune pseudopregnant females. The implantation rates of embryos in the immune rabbits were one-third to one-half that of the controls and, in addition, postimplantation loss was also significantly increased in the testis-immunized group. That the immune response was directed against antigens of sperm and the early embryo and not oocyte antigens was shown by achieving fertilization and normal development with oocytes retrieved from spermimmune female rabbits. Further studies suggested that the antisperm-immune response exerted an embryotoxic effect in the oviducts, which persisted through implantation. ${ }^{9}$

Subsequently, we examined the antifertility effects of immunoglobulins from reproductive tract secretions of sperm-immunized rabbits. IgA antisperm antibodies not only caused inhibition of sperm interaction with ova but also reacted with rabbit morulae and blastocysts resulting in degenerative changes in embryos incubated in vitro that were not observed with IgG antibodies. ${ }^{10,11}$ Additional studies suggested that an antigen(s) from under the sperm plasma membrane was responsible for inducing the antiembryo activity seen with antisperm IgA antibodies. ${ }^{12,13}$ Immunization of female rabbits with plasma membrane components induced antifertilization effects and no postfertilization infertility, whereas immunization with a submembrane preparation induced only the postfertilization effects. In a Western blot procedure, antisperm IgA antibodies detected several antigens in a preparation of rabbit conceptus. ${ }^{14}$

In mice, using rabbit antibodies against murine sperm, two membrane antigens were detected on cleaving embryos; one originated during oogenesis and the other after fertilization at the four-cell stage. ${ }^{15}$ 
We suggest three mechanisms by which antisperm antibodies can affect postfertilization preimplantation embryo survival.

\section{Incorporation of sperm surface antigens into the zygotic membrane}

Mammalian fertilization involves the fusion of sperm and egg surface membranes. The zygote is surrounded by a single plasma membrane that, at least initially, is a mosaic of the membranes of the two gametes. ${ }^{16}$ The plasma membranes of the gametes are fluid, leading to lateral mobility of surface antigens on the haploid germ cells. After gamete fusion, sperm surface antigens continue to move freely over the zygote membrane. ${ }^{17}$ Gabel et al., however, reported that mouse sperm surface molecules labeled with a fluorescein dye showed restricted mobility on embryos. ${ }^{18}$ The sperm molecules remained as a patch on a single blastomere through several cleavages before being internalized.

Antiserum against rabbit semen showed that the sperm antigens were transferred to the membrane of rabbit eggs at the time of fertilization. ${ }^{19}$ Gaunt used a monoclonal antibody directed against a single surface antigen (2D6) of rat sperm, which was located over the entire surface of sperm and was spread laterally over the surface of the oocyte after fusion with the oocyte plasma membrane ${ }^{20}$ Subsequently, the antigen spread on most of the zygote surface and totally disappeared when the zygote developed into two-cell embryos.

In infertile human couples there is evidence indicating that antisperm antibodies, as detected by assays against either whole sperm or the purified sperm antigen (FA1), are able to interfere with fertility. ${ }^{21,22}$ Although the main effect is thought to be inhibition of fertilization, there is evidence suggesting that postfertilization fertility may also be affected. This appears as increased spontaneous abortions in women who conceive while positive for antisperm antibodies when compared with women who conceive and are negative for the antibodies. ${ }^{23-25}$

Recently, Wiley et al. reported that human sera possessing antisperm antibodies as detected by the immunobead binding assay contained antibodies that bound to the oolemma of sperm-penetrated hamster ova, but not to the unpenetrated ova. ${ }^{26}$ The authors suggested that antigens derived from the membrane of the penetrating human sperm were acquired by the vitelline membrane of the oocyte. A study by Bronson and Cooper, however, disputes this conclusion in that they found human sera containing antibodies reactive with the hamster egg membrane independent of the existence of antisperm antibodies. ${ }^{27}$ In addition, absorption of positive sera with sperm cells did not remove the anti-oolemma activity, although the antisperm activity became negative.

The sperm surface antigens that are incorporated into embryos may play a role in normal embryonic development. These sperm surface components on the embryonic membrane may serve as an extranuclear signal and/or a channel for physiologic flux of ions required for oocyte activation.

\section{Embryonic cross-reacting antigens developed after fertilization}

Sperm surface antigens (SSA), which are incorporated into embryonic membranes during fertilization, exist in very small quantity. The studies involving indirect immunofluorescence technique (IFT) have indicated that incorporated SSA stay on the embryonic membrane only for the first few cleavages, after which they are subsequently internalized and degraded. The embryo surface expresses additional antigens which are synthesized de novo at postfertilization stages by expression of diploid heterokaryon. There are numerous reports concerning the expression of cell surface antigens during embryonic development as early as the preimplantation period.

In the animals investigated to date, the early stages of development are regulated by maternally inherited information. The embryonic genome is not expressed until mid two-cell stage in the mouse ${ }^{28}$ and the eightcell stage in sheep. ${ }^{29}$ A recent study on human oocytes and cleaving embryos obtained from human in vitro fertilization (IVF) cases revealed that embryonic gene expression first occurs between the four- and eight-cell stages of development. ${ }^{30}$ During the period when the embryonic genome becomes active, several developmentally related differentiation events occur as the embryo progresses to a multicellular blastocyst. ${ }^{31}$ Many of these antigens may cross-react with the antigens present on the surface of sperm cells. Some of these reported antigens are discussed below.

Cerebellar antigens. The rabbit antiserum raised against murine brain (cerebellum) demonstrated a crossreaction with murine sperm cells, unfertilized and fertilized ova, and preimplantation blastocysts. In subsequent studies, two serologically different cross-reacting antigens, the nervous system antigens (NS-4 and NS-7), were delineated; these were present on the surface of brain, sperm, and early embryo. 31,32

Oncofetal antigens. Murine teratocarcinomas have been extensively studied as a model for normal embryonic development. They retain certain important properties of early developing embryos. Several oncofetal antigens (OFA) that are present on these cells and are shared with sperm and early embryonic surfaces have been delineated. Antisera raised in rabbits by hyperimmunization with small embryoid bodies of the transplantation teratocarcinoma OTT6050 recognize several distinct antigens, some of which were found on the surface of preimplantation murine embryos as well as on murine sperm. ${ }^{33}$ Another major antigen has been characterized on the surface of the nullipotent teratocarcinoma F-9 cell line. The F-9 antigen is a glycoprotein containing two polypeptide chains of $45 \mathrm{kD}$ and $12 \mathrm{kD}$ and is present on early embryo and sperm surface. ${ }^{34}$ The antigen PCC4 that has been delineated is common to multipotential embryonal carcinoma cells, murine spermatozoa, and embryo. ${ }^{35}$ The antiserum raised by allogeneic immunization with teratocarcinoma cell line PYS-2 recognized an antigen "Endo" on male germ cells and embryonic tissue. ${ }^{36}$ Similarly, alloantisera against teratocarcinoma cell line PC13 recognized an antigen on male germ cells and embryonic tissues. ${ }^{37}$ These studies indicate that there are several antigens on the surface of various teratocarcinoma cell lines that are shared with sperm and the preimplantation embryo.

Active immunization of female mice against teratocarcinoma cells has been reported to induce infertility that involved fertilization failure and preimplantation embryonic mortality. ${ }^{38}$ Another study reported that immunization with OTT6050 cells reduced fertility in both 
male and female mice. ${ }^{39}$ Again, the allo- and xenoantisera to these cells also inhibited in vitro fertilization. Various studies have demonstrated that xenogenic antisera raised against F-9 cell lines inhibit in vitro embryo development in mice and rabbits. ${ }^{40}$ It is also of interest to note that sera from some vasectomized mice reacted with both sperm cells and F-9 cells. ${ }^{41}$ These cumulative data indicate that some of these oncofetal antigens shared among teratocarcinoma cell lines, sperm, and embryonic tissue may be relevant to fertilization and/or embryonic development.

Histocompatibility antigens. There are several other antigens that may be shared between embryo and sperm. The major histocompatibility complex (MHC) antigens are called human leukocyte antigens (HLAs) in humans and histocompatibility antigens $(\mathrm{H}-2)$ in mice. In humans, a controversy exists as to whether human sperm express a haploid component of HLAs. However, recent experiments using monoclonal antibodies have failed to find HLA expression on sperm. ${ }^{42}$ The indirect data on immunology of human infertility, recurrent abortions, and pregnancy disorders indicate that HLAs are expressed on the placental trophoblast at the maternalfetal tissues. ${ }^{43}$ Because of obvious reasons, little work has been done on HLA expression on preimplantation human embryos. Advancements in in vitro fertilizationembryo transfer (IVF-ET) technology may help to answer some of these questions.

\section{Indirect effects of antisperm antibodies on embryo development}

Antisperm antibodies may indirectly affect embryo development through transport into the oocyte at fertilization and exertion of their effects during the cleavage stages. This phenomenon was first reported by Kiddy et al. $^{2}$ in rabbits and further explored by us using monoclonal antibodies (MCA). ${ }^{44,45}$ Lee et al. also found similar effects in mice passively immunized with MCA. ${ }^{46}$ Two MCAs produced against rabbit sperm inhibited fertility in female rabbits artificially inseminated with treated sperm. ${ }^{44}$ Fertilization appeared to be unaffected, but after a few cleavages the embryos began to degenerate either in vivo or upon in vitro incubation. The effect was not directly on the embryos, as the MCAs failed to react with blastocysts, and the development of zygotes was not affected by in vitro culture in the antibodies. Using immunoaffinity chromatography a $63-\mathrm{kD}$ glycoprotein antigen was isolated from rabbit germ cells referred to as GA-1. ${ }^{45,47}$ The antigen was immunogenic in both mice and rabbits, inducing polyclonal antisera that inhibited fertility in both species via passive immunization. A significant degree of postfertilization infertility was also induced in both mice and rabbits after active immunization with GA-1. That the effect occurred postfertilization was confirmed by in vitro studies in mice in which fertilization was unaffected by the antibodies. Antibodies against GA-1 were also without effect on penetration of zona-free hamster eggs by capacitated human sperm, although the antibodies were shown to be bound to the sperm surface. The data suggest that sperm had to carry these antibodies into the ova during fertilization to exert the antifertility effect. This effect did not appear to be due to parthenogenic activation or polyspermy. The antibodies may affect some extranuclear factor essential for continued embryo viability or development.
Recently, the advent of recombinant DNA technology has made available different pure lymphokines and monokines for research on cell-mediated immunity and fertility. A variety of these molecules, especially the interferons, colony-stimulating factors, B-cell growth factors, interleukins, and tumor necrosis factor have been investigated for cytotoxic activity against many types of developing cells, including gametes and preimplanting embryos. ${ }^{48,49}$ Our studies indicate that these factors are secreted by presensitized lymphocytes upon activation by specific sperm antigens. 50 The factors secreted in the conditioned cell supernatants had detrimental effects on sperm cells and developing embryos in vitro. Whether such a mechanism(s) operates in vivo needs further study.

\section{CONCLUSION}

The evidence suggests that sperm cells and preimplantation embryos share antigen specificities that arise from contributions from the plasma membrane of the fertilizing sperm cell and the expression of the embryonic genome. It appears that plasma membrane molecules from the sperm cell play a role in early embryo development and cleavage or, at least, antibodies directed against some components may affect these stages. Therefore, antisperm antibodies present in the female reproductive tract are potentially capable of interfering with postfertilization preimplantation fertility.

\section{REFERENCES}

1. Katsh S. Immunology, fertility and infertility: A historical survey. Am J Obstet Gynecol. 1959; 77:946-956.

2. Kiddy CA, Stone WH, Casida LE. Immunologic studies on fertility and infertility: II. Effects of treatment of semen with antibodies on fertility in rabbits. J Immunol. 1959; 82:125-130.

3. Behrman SJ, Otani Y. Transvaginal immunization of the guinea pig with homologous testis and epididymal sperm. Int J Fertil. $1963 ; 8: 829-834$.

4. Otani Y, Behrman SJ, Porter CW, Nakayama M. Reduction of fertility in immunized guinea pigs. Int J Fertil. 1963; 8:835-839.

5. Sawada Y, Behrman SJ. Reduction of fertility in rabbits by isoimmunization: Mechanism of action. Proc Fifth World Congr Ex cerpta Medica Foundation. 1966; 133:758-764.

6. Kiddy CA, Rollins RM. Infertility in female guinea pigs injected with testis. Biol Reprod. 1973; 8:545-549.

7. Tung KSK, Goldberg EH, Goldberg E. Immunological consequence of immunization of female mice with homologous spermatozoa: Induction of infertility. J Reprod Immunol. 1977; 1:145-158.

8. Menge AC. Immune reactions and infertility. J Reprod Fertil [Suppl]. 1970; 10:171-186.

9. Menge AC, Burkons DM, Friedlander GE. Occurrence of embryo mortality in rabbits isoimmunization against semen. Int $J$ Fertil. 1972; 17:93-96.

10. Menge AC, Lieberman ME. Antifertility effects of immunoglobulins from uterine fluids of semen-immunized rabbits. Biol Reprod. $1974 ; 10: 422-428$.

11. Menge AC, Rosenberg A, Burkons DM. Effects of uterine fluids and immunoglobulins from semen-immunized rabbits on rabbit embryos cultured in vitro. Proc Soc Exp Biol Med. 1974; 145:371378.

12. Menge AC, Peegle H, Riolo ML. Sperm fractions responsible for immunologic induction of pre- and postfertilization infertility in rabbits. Biol Reprod. 1979; 20:931-937.

13. Menge AC, Peegel $H$. Antibody activities of serum and uterine fluid samples from rabbits isoimmunized against sperm fractions. Arch Androl. 1980; 4:171-178.

14. Naz RK, Bradford CR, Menge AC. Iso-antigenicity of rabbit sperm, testis, and their extracts as demonstrated by Western blot enzyme immunobinding procedure. Arch Androl. 1984; 13:279-287.

15. Menge AC, Fleming $\mathrm{CH}$. Detection of sperm antigens on mouse ova and early embryos. Dev Biol. 1978; 63:111-117.

16. Bedford JM. An electron microscopic study of sperm penetration into the rabbit egg after natural mating. Am J Anat. 1972; 133:213254.

17. Johnson M, Edidin M. Lateral diffusion in plasma membrane of 
mouse eggs is restricted after fertilization. Nature. 1978; $272: 448$ 450

18. Gabel CA, Eddy EM, Shapiro BM. Regional differentiation of the sperm surface as studied with ${ }^{125}$ I-diiodofluorescein isothiocyanate, an impermeant reagent that allows isolation of the labeled components. J Cell Biol. 1979; 82:742-754.

19. O'Rand MG. The presence of sperm-specific isoantigens on the egg following fertilization. J Exp Zool. 1977; 202:267-293.

20. Gaunt SJ. Spreading of a sperm surface antigen within the plasma membrane of the egg after fertilization in the rat. J Embryol Exp Morphol. 1983; 75:259-270.

21. Menge AC. Clinical immunological infertility: Diagnostic measures, incidence of antisperm antibodies, fertility and mechanism In: Dhindsa DS, Schumacher GB, eds. Immunological Aspects of Infertility and Fertility. New York; Elsevier-North Holland 1980;205-225.

22. Naz RK. The fertilization antigen: Applications in immunocontra ception and infertility in humans. Am J Reprod Immunol Microbiol. 1988; 16:21-27.

23. Jones WR. Immunological aspects of infertility. In: Scott JS, Jones WR, eds. Immunology of Reproduction. London; Academic Press, $1976 ; 375-413$.

24. Mathur S, Baker ER, Williamson HO, Derrick FC, Teague KJ Fudenberg HH. Clinical significance of sperm antibodies in infertility. Fertil Steril. 1981; 36:486-495.

25. Menge AC, Medley NE, Mangione CM, Dietrich JW. The incidence and influence of antisperm antibodies in infertile human couple on sperm-cervical mucus interactions and subsequent infertility Fertil Steril. 1982; 38:439-446.

26. Wiley LM, Obasaju MF, Overstreet JW, Cross NL, Hanson FW, Chang RJ. Detection of antisperm antibodies: Their localization to human sperm antigens that are transferred to the surface of zonafree hamster oocytes during the sperm penetration assay. Fertil Steril. 1987; 48:292-298.

27. Bronson RA, Cooper GW. Detection in human sera of antibodies directed against the hamster egg oolimma. Fertil Steril. 1988; 49:493-496

28. Braude P, Pelham H, Flach G, Lobatto R. Post-transcriptional control in the early mouse embryo. Nature. 1979; 282:102-105.

29. Crosby IM, Gandolfi F, Moor RM. Control of protein synthesis during early cleavage of sheep embryos. J Reprod Fertil. 1988, 82:769-775.

30. Braude P, Bolton V, Moore S. Human gene expression first occurs between the four- and eight-cell stages of preimplantation development. Nature. 1988; 332:459-461.

31. Solter D, Schachner M. Brain and sperm cell surface antigen (NS 4) on preimplantation mouse embryo. Dev Biol. $1976 ; 52: 98-104$

32. Chaffee JK, Schachner M. NS-7 (nervous system antigen-7): A cell surface antigen of mature brain, kidney and spermatozoa shared by embryonal tissues and transformed cells. Dev Biol. 1978 62:185-192

33. Webb C. Characterization of antisera against mouse teratocarcinoma OTT6050: Molecular species recognized on embryoid bodies, preimplantation embryos and sperm. Dev Biol. 1980; 76:203-214.

34. Artzt K, Dubois PH, Bennett D, Condamine H, Babinet C, Jacob
F. Surface antigens common to mouse cleavage embryos and primitive teratocarcinoma cells in culture. Proc Natl Acad Sci USA 1973; 70:2988-2992.

35. Gachelin G, Kemler R, Kelly F, Jacob F. PCC4; a new cell surface antigen common to multipotential embryonal carcinoma cells spermatozoa, and mouse early embryo. Dev Biol. 1977; 57:199_ 209.

36. Artzt K, Hamburger L, Jakob H, Jacob H. Embryonic surface antigens: A "quasi-endodermal" teratoma antigen. Dev Biol. 1976 51:152-157.

37. Randle BJ. Cosegregation of monoclonal antibody reactivity and cell behaviour in the mouse preimplantation embryo. J Embryol Exp Morphol. 1982; 70:261-278.

38. Hamilton MS, May RD, Beer AE, Vitetta ES. The influence of immunization of female mice with F-9 teratocarcinoma cells on their reproductive performance. Transplant Proc. 1979; 11:1069. 1072 .

39. Webb CG. Decreased fertility in mice immunized with teratocarcinoma 0TT6050. Biol Reprod. 1980; 22:670-675.

40. Johnson MH, Chakraabarty J, Hanyside AH, Willison K, Stern P The effect of prolonged decompaction on the development of the preimplantation mouse embryo. J Embryol Exp Morphol. 1979 54:241-261.

41. Anderson DJ, Adams PH, Hamilton MS, Alexander NJ. Antisperm antibodies in mouse vasectomy sera react with embryonal teratocarcinoma. J Immunol. 1983; 131:2908-2912.

42. Anderson DJ, Bach DL, Yunis EJ, DeWolf WC. Major histocompatibility antigens are not expressed on human epididymal sperm. $J$ Immunol. 1982; 129:452-454.

43. Menge AC, Beer AE. The significance of human leukocyte antigen profiles in human infertility, recurrent abortion and pregnancy disorders. Fertil Steril. 1985; 43:693-695.

44. Naz RK, Saxe J, Menge AC. Inhibition of fertility in rabbits by monoclonal antibodies against sperm. Biol Reprod. 1983; 28:249 254

45. Naz RK, Rosenblum BR, Menge AC. Characterization of a membrane antigen from rabbit testis and sperm isolated by using monoclonal antibodies and effect of its antiserum on fertility. Proc Natl Acad Sci USA. 1984; 81:857-861.

46. Lee GC-Y, Wong E, Zhang J-H. Inhibitory effects of monoclonal sperm antibodies on the fertilization of mouse oocytes in vitro and in vivo. $J$ Reprod Immunol. 1986; 9:261-274.

47. Naz RK, Poffenberger RJ, Menge AC. Reduction of fertility in fe male rabbits and mice actively immunized with a germ cell antigen (GA-1) from the rabbit. J Reprod Immunol. 1986; 9:163-173.

48. Faikih H, Baggett B, Holtz G, Tsang K, Lee J, Williamson H Interleukin $\mathrm{I}$ : A possible role in the infertility associated with endometriosis. Fertil Steril. 1987; 47:213-217.

49. Hill JA, Florina H, Anderson DJ. Products of activated lymphocytes and macrophages inhibit mouse embryo development. J Im munol. 1987; 139:2250-2254.

50. Naz RK, Mehta K. Cell mediated immune responses to sperm antigens: Effects on murine sperm and embryos. Cell Immunol. (in press.) 